7 Alexander WJ, MacMillan BG, Law E, Kittur DS. Treatment of severe burns with widely meshed skin autograft and meshed skin allograft overlay. $\mathcal{F}$ Trauma 1981;21:433-8.

8 Frame JD, Sanders R, Goodacre TEE, Morgan BDG. The fate of meshed allograft skin in burned patients using cyclosporin immunosuppression. Br f Plast Surg 1989;42:27-34.

9 Alsbjörn BF, Sørensen B. Grafting with epidermal Langerhans' cell depressed cadaver split skin Burns 1985;11:259-63.

10 Rheinwald JG, Green H. Serial cultivation of strains of human epidermal keratinocytes: the formation of keratinizing colonies from single cells. Cell 1975;6:331-44.

11 O'Connor NE, Mulliken JB, Banks-Schlegel S, Kehinde O, Green H. Grafting of burns with cultured epithelium prepared from autologous epidermal cells. Lancet 1981 ; i:75-8.

12 Gallico GG, O'Connor NE, Compton CC. Permanent coverage of large burn wounds with autologous cultured human epithelium. $N$ Engl f Med 1984;311:448-51.

13 Morhenn VB, Benike CJ, Cox AJ, Charron DJ, Engleman EG. Cultured human epidermal cells do not synthesize HLA-DR. $f$ Invest Dermatol 1982;78:32-7.

14 Burt AM, Pallett CD, Sloane JP, et al. Survival of cultured allografts in patients with burns assessed with probe specific for $Y$ chromosome. BMf 1989;298:915-7.

15 Auböck J. Hautersatz durch Kultivierte Keratinozyten. Z Hautkr 1988:63:565-7.

16 Wubock J. Hautersatz durch Kulterte KR autografts show abnormal reconstitution of anchoring fibrils. FAMA 1988;259:2566-71.

17 Cuono C, Langdon R, McGuire J. Use of cultured epidermal autografts and dermal allografts as skin replacement after burn injury. Lancet 1986;i:1123-4.

8 Langdon RC, Cuono CB, Birchall N, et al. Reconstitution of structure and cell function in human skin grafts derived from cryopreserved allograft dermis and autologous cultured keratinocytes. f Invest Dermatol 1988;91:478-85.

19 May SR, Still JM, Atkinson RN. Recent developments in skin banking and the clinical uses of cryopreserved skin. I Med Assoc Ga 1984;257:233-6.

20 Burke JF, Yannas IV, Quinby WC, Bondoc CC, Jung WK. Successful use of a physiologically acceptable artificial skin in the treatment of extensive burn injury. Ann Surg 1981;194:413-28.

21 Boyce ST, Hansbrough JF. Biologic attachment, growth and differentiation of cultured human epidermal keratinocytes on a graftable collagen and chondroitin-6-sulphate substrate. Surgery 1988;103:421-31.

22 Heimbach D, Luterman A, Burke J, et al. Artificial dermis for major burns. A multi-cente randomized trial. Ann Surg 1988;208:313-20.

23 Hansbrough JF, Boyce ST, Cooper ML, Foreman TJ. Burn wound closure with cultured autologous keratinocytes and fibroblasts attached to a collagen-glycosaminoglycan substrate. fAMA 1989;262:2125-30.

24 Bell E, Sher S, Hull B, et al. The reconstitution of living skin. $\mathcal{F}$ Invest Dermatol 1983;81(suppl): 2-10.

25 Wassermann D, Schlotterer M, Toulon A, et al. Preliminary clinical studies of a biological skin equivalent in burned patients. Burns 1988;14:326-30

6 Hull BE, Finley RK, Miller SF. Coverage of full-thickness burns with bilayered skin equivalents: a preliminary clinical trial. Surgery 1990;107:496-502.

27 Nanchahal J, Otto WR, Dover R, Dhital SK. Cultured composite skin grafts: biological cultured skin equivalents permitting massive expansion. Lancet 1989;ii:191-3.

28 Gielen V, Faure M, Mauduit G, Thivolet J. Progressive replacement of human cultured epithelium allograft by recipient cells as evidence by HLA class I expression. Dermatologica 1987;175: 166-70.

29 Chamson A, Germain N, Claudy A, Perier C, Frey J. Study of basement membrane formation in dermal-epidermal recombinants in vitro. Arch Dermatol Res 1989;281:267-72.

30 Tinois E, Tiollier J, Dumas H, Thivolet J. In vitro and post-transplantation differentiation of human keratinocytes grown on human type IV collagen film of a bilayered dermal substitute [Abstract]. F Invest Dermatol (in press).

\section{Does passive smoking cause heart disease?}

\section{The evidence is strong enough to warrant measures to reduce exposure}

Active smoking is the most readily preventable cause of coronary heart disease. In 1986 the United States Surgeon General identified passive smoking as a cause of lung cancer and called for further research on the relation between passive smoking and cardiovascular disease. ${ }^{1}$ Since then six cohort studies $^{2-9}$ and one case-control study ${ }^{10}$ published in English have examined this association and an answer is beginning to emerge. The cohort studies were of variable size and included participants from the United States, ${ }^{2-57}$ Scotland, ${ }^{6}$ and Japan. ${ }^{89}$ Measurement of exposure to passive smoking was based on questionnaire responses; in only one study was there objective evidence of exposure to passive smoke and the same study had information on workplace exposure. ${ }^{+}$All but one study ${ }^{5}$ followed up individuals; and one study measured the stability of smoking rates part way through the follow up. ${ }^{7}$ Several coronary heart disease end points were examined, and all the studies tried to control for other risk factors.

Collectively the cohort studies suggest a positive association between passive smoking and death from heart disease with relative risks ranging from $1 \cdot 2$ to $2 \cdot 7$. There are several possible explanations for the observed association; these include chance, bias (including publication bias), and confounding - or the association could be causal. Chance is an unlikely explanation given the precision of the results in some studies; the combined relative risks were significant in both men and women."

Systematic error (bias) in measuring passive smoking is a possible explanation. ${ }^{12}$ If the passive smoking group included active smokers who had been incorrectly classified as nonsmokers the relative risk in this group would have been inflated. Only a small part of the increase in the risk of lung cancer associated with passive smoking among non-smokers, however, could have been due to this type of misclassification. ${ }^{13}$ Active smoking increases the risk of lung cancer by about 10-fold, but its effect on heart disease is much less (roughly a doubling of risk), so misclassification is highly unlikely to be the sole cause of the observed increase in the risk of heart disease associated with passive smoking. Furthermore, since many non-smokers who do not live with smokers are known to be exposed to smoke from other sources, particularly at work, the effect of passive smoking is likely to be underestimated..$^{13}$ Publication bias, the greater likelihood of studies with positive results to be published compared with those with negative results, does not explain the association of passive smoking with lung cancer ${ }^{14}{ }^{15}$; there is no reason to believe that it explains the association with coronary heart disease.

Confounding - that is, mixing of effects - is the most likely non-causal explanation for the observed association. Confounding might account for some or all of the association if passive smoking were associated in the population studied with other risk factors for heart disease and if these associations had been inadequately controlled in either the study design or the analysis. All six studies controlled for age, and four comprehensively controlled for the major cardiovascular disease risk factors ${ }^{2467}$; the impact on the relative risk of controlling for these risk factors was in general minimal. Since non-smokers tend to come from healthy families, however, the effects of unknown confounders might still be important. ${ }^{16} 17$

A judgment is required to determine whether the association is causal. The temporal association is correct; the association is plausible given our knowledge of the effects of active smoking and the effect of passive smoking on other health outcomes'; physiological and biochemical studies suggest possible mechanisms ${ }^{18}$; there is some evidence of a dose response relation ${ }^{67}$; and there is consistency of results among the cohort studies. Differences between sidestream and mainstream smoke, the absence of a truly non-exposed control group in studies of active smoking, and a greater susceptibility of passive smokers to the health damaging effects of tobacco smoke may explain the apparently high relative risks of coronary heart disease associated with passive smoking compared with the relative risks caused by active smoking.

The available evidence does therefore suggest that passive smoking is a cause of coronary heart disease. Nevertheless, further epidemiological studies are required in various settings. In particular there is a need for large, well designed case-control studies that accurately measure recent and past passive smoking at home and at work and adjust for all known potential confounders, particularly socioeconomic factors. Follow up studies of people at high risk, such as survivors of a myocardial infarction, may also be worth while.

From the public health perspective this association is important because coronary heart disease is much more common than respiratory disease; most of the deaths attributed to passive smoking in the United States and New Zealand have been caused by coronary heart disease. ${ }^{119}$ 
Passive smoking is easier to control (by legislation and regulation) than active addictive smoking. The public health implications of the available evidence warrant continued efforts to reduce the public's exposure to other people's tobacco smoke.

Professor of Community Health,

ROBERT BEAGLEHOLE

School of Medicine,

University of Auckland,

Auckland,

New Zealand

1 United States Public Health Service. The health consequences of involuntary smoking: a report of the Surgeon General. Rockville: Department of Health and Human Services, 1986:105-6.

2 Garland C, Barrett-Connor E, Suarez L, et al. Effects of passive smoking on ischemic heart disease mortality of nonsmokers. Am J Epidemiol 1985;121:645-50.

3 Erratum. Am $\mathcal{F}$ Epidemiol 1985;122:1112.

4 Svendsen KH, Kuller LH, Martin MJ, Ockene JK. Effects of passive smoking in the multiple risk factor intervention trial. Am J Epidemiol 1987;126:783-95.

Helsing KJ, Sandler DP, Comstock GW, Chee E. Heart disease mortality in nonsmokers living with smokers. Am f E pidemiol 1988;127:915-22.

6 Hole DJ, Gillis CR, Chopra C, Hawthorne VM. Passive smoking and cardiorespiratory health in a general population in the west of Scotland. BMJ 1989;299:423-7.

7 Humble C, Croft J, Gerber A, et al. Passive smoking and 20-year cardiovascular disease mortality among nonsmoking wives, Evans County, Georgia. Am f Public Health 1990;80:599-601.

8 Hirayama T. Lung cancer in Japan: effects of nutrition and passive smoking. In: Mizell M, Correa P, eds. Lung cancer causes and prevention. New York: Verlag Chemie International, 1984:175-94.
. Hirayama T. Passive smoking. $N Z$ Med f 1990;103:20

10 Lee PN, Chamberlain J, Alderson MR. Relationship of passive smoking to risk of lung cancer and other smoking-associated diseases. Brf Cancer 1986;54:97-105.

11 Wells AJ. An estimate of adult mortality in the United States from passive smoking. Environment International 1988;14:249-65.

12 Lee PN. Passive smoking and cardiorespiratory health in Scotland. BMf 1989;299:742.

13 Wald NJ, Nanchahal F, Thompson SG, Cuckle HS. Does breathing other people's smoke cause lung cancer? $B M \mathcal{F}$ 1986;293:1217-22.

14 Vandenbroucke JP. Passive smoking and lung cancer: a publication bias? BMf 1988;296:391-2. 15 Wells AJ. Passive smoking and lung cancer: a publication bias? BMJ 1988;296:1128

16 Friedman GD, Petitti DB, Bawol RD. Prevalence and correlates of passive smoking. Am $\mathcal{f}$ Public Health 1983;73:401-5.

17 Koo LC, Ho JH-C, Rylander R. Life-history correlates of environmental tobacco smoke: a study on nonsmoking Hong Kong Chinese wives with smoking versus nonsmoking husbands. Soc Sci Med 1988;26:751-60.

18 Glantz SA, Parmley WW. Passive smoking and heart disease: epidemiology, physiology, and biochemistry. Circulation (in press)

19 Kawachi I, Pearce NE, Jackson RT. Deaths from lung cancer and ischaemic heart disease due to passive smoking in New Zealand. N Z Med $\mathcal{F}$ 1989;102:337-40.

\section{Does treatment for cervical intraepithelial neoplasia affect fertility and pregnancy?}

\section{Little to worry about}

One of the main advantages of an increasingly conservative approach to managing cervical intraepithelial neoplasia, and even microinvasive carcinoma of the cervix, is that the potential for child bearing is maintained. But does such treatment compromise either fertility or the outcome of a subsequent pregnancy?

There are three potential causes of infertility after cone biopsy or destructive methods of treatment. The first is cervical stenosis, which would have to be complete to prevent sperm from entering the endometrial cavity and is uncommon. ${ }^{12}$ Luesley et al, however, reported symptomatic cervical stenosis in $8 \%$ of 915 patients, with $1.3 \%$ experiencing amenorrhoea due to haematometra. ${ }^{3}$ This complication seems to be a particular risk if the cone biopsy is performed during postpartum amenorrhoea. ${ }^{4}$ A second, somewhat more common, problem is secondary infection at the site of treatment, which may occur in up to $10 \%$ of cases. Potentially these patients are at risk of developing ascending infection with resulting tubal damage, but no studies have documented this. Lastly, we have seen several patients who have had infertility problems, particularly after laser ablative treatment, allegedly due to absence of cervical mucus. All treatment methods destroy many of the mucus secreting glands of the cervix, and such destruction may alter both the volume and the physical properties of cervical mucus. Nevertheless, there are no reports on mucus problems, or indeed on subsequent fertility, after laser treatment for cervical intraepithelial neoplasia. Weed et al postulated that altered mucus might be a problem after cryosurgery, but failed to prove it in a series of 412 patients. ${ }^{5}$ They noted good spinnbarkeit and ferning in patients who were ovulating. In 30 patients treated by cryosurgery for cervical ectropion, who had normal cytological and colposcopic findings, Baram et al thought that this treatment improved the characteristics of cervical mucus. ${ }^{6}$

Most workers who have studied fertility after treatment of cervical intraepithelial neoplasia have assessed it by comparing the numbers of patients at risk of pregnancy with the number of pregnancies achieved ${ }^{7-9}$; others have compared the numbers of patients becoming pregnant with those complaining of infertility. ${ }^{10}$ None have found any effect of treatment on subsequent fertility.

Complications of pregnancy after treatment of cervical intraepithelial neoplasia are more familiar, though these too are uncommon and seem to be confined largely to patients who have undergone cervical conisation. Such problems may include cervical dystocia, leading to caesarean section. ${ }^{1}$ The incidence of second trimester abortion also seems to be increased after cervical conisation: the incidence was $15 \%$ in 88 pregnancies in 77 women. ${ }^{11}$ Among 66 patients proceeding beyond 28 weeks preterm delivery occurred in 12 , with birth weights of under $2500 \mathrm{~g}$ in $14 .^{12}$ The mean duration of labour was $8 \cdot 5$ hours for 55 multigravid patients who had undergone cone biopsy compared with $6 \cdot 3$ hours in 205 controls. Nevertheless, in their review of published studies, which they criticised for lack of detail about patients and limited use of controls, Weber and Obel concluded that conisation did not lead to an increased frequency of spontaneous abortion or to increased perinatal mortality. ${ }^{13}$ Likewise, Buller and Jones concluded that spontaneous abortion rates, premature delivery, and caesarean section rates were not significantly altered by cervical conisation in 166 patients who were followed up out of an original series of $314 .^{10}$

The findings for cryosurgery and laser vaporisation for cervical intraepithelial neoplasia seem even more reassuring. In two series of patients who underwent cryosurgery the authors found no adverse effect on the subsequent outcome of pregnancy, ${ }^{14}{ }^{15}$ and similar conclusions came from two series of patients treated by laser vaporisation. ${ }^{16}{ }^{17}$ Fertility has not been evaluated after loop diathermy excision of the cervical transformation zone, but Prendiville et al reported on two women treated at six weeks of pregnancy who had no subsequent complications. ${ }^{18}$

Patients undergoing conservative treatment for cervical intraepithelial neoplasia can therefore be largely reassured about their subsequent fertility and outcome of pregnancy, particularly if the colposcopic findings satisfy the requirements for destructive treatment techniques. Patients undergoing cone biopsy of the cervix may, however, have a slightly increased risk of complications in a subsequent pregnancy.

R H HAMMOND

Senior Registrar in Obstetrics and Gynaecology

D K EDMONDS

Consultant Obstetrician and Gynaecologist

Queen Charlotte's and Chelsea Hospital,

London W6 0XG

\footnotetext{
McLaren HC. Conservative management of cervical precancer. Fournal of Obstetrics and Gynaecolog of the British Commonzuealth 1967;74:487-92.

Pittaway DE, Daniell J, Maxson W, Boehm F. Reconstruction of the cervical canal after complete postconization obstruction. A case report. J Reprod Med 1984;29:339-40.
} 